\title{
Study on the Construction of Innovative Practice Base for M.E. Graduate
}

\author{
Qi Zhou and Zaigen Mu \\ University of Science and Technology Beijing, Beijing, 100083, China
}

Keywords: M.E.; Professional degree; Industry-Academy-Research cooperation; Innovative practice base.

\begin{abstract}
The Construction of Innovative Practice Base for M.E. program is an important part of innovation education for full-time M.E. degree program. At present, most of the students in full-time M.E. program are from the fresh university graduates, for which the practice teaching time should be not less than one year in principle. Therefore, an adequate high-quality engineering professional practice, which could bring up the practical ability and innovation capacity of M.E. graduate, is the important guarantee of the quality of the professional degree education. Civil and Environmental Engineering School of University of Science and Technology Beijing has done a beneficial exploration on the Construction of Innovative Practice Base for M.E. graduate of Architecture and civil engineering and built the innovative practice base for university-enterprise cooperation joint training of M.E graduate. Moreover, referring to the current situation analysis and existing problems, Civil and Environmental Engineering School of University of Science and Technology Beijing proposed a program and system of a closer construction of innovative practice base for M.E. graduate, which ensure the improvement of the practical ability and innovation capacity of students in M.E. program.
\end{abstract}

\section{Introduction}

Graduate education is the main way to train high-level personnel and also an important part of the national innovation system. Since the reform and opening up, China has made significant achievements on master education and basically achieved the domestic strategic target of high-level personnel training. But generally speaking, graduate education can not fully meet the diverse needs of economic and social development, there is still a large gap between domestic cultivation quality and the international advanced level. In the year of 2009, China began to increase the number of recruiting full-time master degree. In 2010 and 2011, according to admissions policies and relevant national documentation, it will become an important task of the degree and the development of graduate education in the future and it will become the mainstream model of graduate education. Being occupational and applicable, the full-time professional degree, determines that university-enterprise joint training model is an effective means, and the innovative practice base for university-enterprise cooperation joint training of M.E graduate as platform, is an effective measure to achieve joint training goal.

\section{Present Problems during the Graduate Education}

With the continuing enrollment of all kinds of graduates, students increased dramatically in a short time, while resources supporting the educational are unlikely to achieve simultaneous growth in such a short time, so postgraduate education and training issues appears one after another, the main performance shows as blow:

- Because of the shortage of faculty, students couldn't get fully guidance; Because of the inadequate funding for graduate education, the majority of graduate laboratory facilities, learning conditions are lagging behind the pace of development of graduate education; Some instructors do not have research projects and research support for a long time, which leading to lack of research funding, lagging research capability; while some instructors load overweight, one instructor being busy guiding dozens of graduate students. There are many factors that led to the unevenness among 
tutor teams, and discouraged grow-up research, both on quantity and quality, which to some degree, affected the quality of postgraduate training, which restricts its development.

- At present, for some joint training base, the form and content of industry-academy-research cooperation are old and single , and the cooperation aiming at pursuing direct benefit emphasis too much on short-term benefits, and the majority is project-based cooperation, long-term strategic-level cooperation is the minority. Instead of the ongoing industry-academy-research cooperation incentives, joint innovation level is generally low and the internal management and the organization of the base is loose and it lacks broad-based cooperation between schools and enterprises. Many bases are scattered research cooperation between universities and enterprises, rather than playing a role in innovation practice base.

- There are some joint training base lacking high-level core research leader, and for those bases, there is no scientific research and innovation team which works closely, and most bases also belong to combat mode of two or three people. The concept of collaborative innovation didn't penetrate into the research of school and enterprises, and failed to better promote cohesion of the research team of the bases as well as inspiring individuals innovation potential. On the other hand, due to the lack of collaborative innovation, the resulting cooperative achievement failed to achieve the desired effect, the level of the collaborative research has been unable to improve and further weaken the basis for bilateral cooperation between schools and enterprises, resulting in mere formality of some university-enterprise cooperation, instead of substantive innovation achievement.

- When graduate students conduct scientific research in the enterprise, there won't be any output in a short time, but enterprises should bear the risk of failure, the corporate doesn't get significant economic benefits; and it lacks the social evaluation system for corporate being involved in personnel training at present, companies can't get social benefits, so companies are not enthusiastic. In addition, there is no relevant policy for the management of the graduate practice base or standardized protocol to make the responsibilities, rights and benefits of school and enterprise clear at present and some practice base is the enterprises cooperated with the transverse project of the mentor. As the subject is completed, there is no practice base and when there comes any problem and contradictions in the process of cooperation, inappropriate treatment could easily lead to rupture of university-enterprise cooperation.

\section{Thinking on Working out the Existing Problems during the M.E. Program}

Given the Current situation analysis and existing problems of full-time professional degree graduate of the above, we propose closer projects of Master of Engineering Innovation Practice postgraduate training base construction, which is closer to the demand of full-time M.E. professional degree graduate training objectives that is" culture applications, complex high-level engineering and project management talent "and to be able to" grasp the basic theory are engaged in the field, methods and means of advanced technology and work independently on engineering design, project implementation, engineering studies, project development, project management and other capacity "in a certain direction of the field, written in the" about forwarding the guiding training program notification of the full-time master professional degree graduate", by the Office of Academic Degrees Committee of the State Council. To improve the ability of engineering practice of these aspects above, university teaching theoretical knowledge in the classroom and being engaged in scientific research and experimental training in the laboratory is not enough. Only by being in a real engineering practices environment, in which one hand they can consolidate the theoretical knowledge learned, on the other hand by cooperatively working with industrial engineer for some time they can go into contact with the production practice, experience work scenarios and job requirements of the practical engineering project development, understand the operation and management of enterprises, form teamwork, ethics and communication skills, can M.E. graduates develop their own good engineering professionnalism, as well as enhance engineering practice and innovative ability, and gradually become a qualified high-level application-oriented projects technical and project management personnel. 


\section{The Features and Innovations of Our Construction of Professional Degree Graduate Innovation Practice Base}

From the perspective of the feasibility of the study, considering currently engineering and technical personnel engaged in research and development of shortage, it provides a broad space for enterprises to absorb graduate students. At present, China's colleges and universities have the ability to undertake major research and there is a strong scientific research strength, which has been widely integrated into the national innovation system. Thus, through the establishment of postgraduate training base for innovative practices, human resources and research capacity of universities will inject fresh vitality into enterprise innovation and promote technological innovation and cutting-edge product development continuously improving the level of production and R \& D capabilities, and some enterprises take the initiative to set up named institutes or research centers in the universities, while others are made to work together with university on research topics. On the basis of agreement of both sides, the modern corporate and universities build innovative practice postgraduate training base, which is an inevitable trend feasible. In a word, "practice and exploration of industry-academy-research cooperative education cultivating innovative talents" in the "21st Century Education Revitalization Action Plan" will be prioritized as an opportunity by the Ministry of Education. Carrying out industry- academy-research education in the postgraduate training and building out school full-time M.E. professional degree postgraduate training innovation practice base has a better policy and social advantages and can provide a good external environment and institutional guarantee for this new training mode.

- Establish incentive mechanism of innovation for engineering graduate students. Develop a personalized training plan according to graduate academic interests, knowledge structure and ability level of students. Explore innovative potential of graduate students and graduate students are encouraged to propose research topic with innovative value, and then doing the research under the guidance of the mentor and team, and the enterprises provide the necessary conditions to support the training.

- Create a favorable growth of talent and innovation research environment. Innovation practice base performs academic reporting system for everyone involved, regularly or irregularly those researcher and postgraduate of painstaking research and accomplishments show and share their academic achievements, and sometimes academic report will be combined with the engineering graduate programs training of graduate students.

- Take a two-way communication, to improve the level of innovation practice base researchers. Which means regularly employing experts in relevant fields to the base classes, and encouraging young scientific and technical personnel studying for a PhD base actively to improve the innovation ability and overall quality of both schools and enterprises mentor young teachers and enterprises professionals to achieve a win-win aim and sustainable base development, thus leading to the result of the improvement of the practical ability and the ability to solve practical problems of production and innovation of M.E. graduate students.

\section{Acknowledgements}

This work was financially supported by the Graduate Education Development Foundation of University of Science and Technology Beijing (20131111).

\section{References}

[1] Jiaquan Wang, Yiwu Tang, Huiqin Wu. Construction and Exploration of Research Team of Graduate Joint Training Base Based on the Collaborative Innovation, Popular Science \& Technology, Vol. 15, No. 5, (2013), p. 164-166.

[2] Guijuan Lin, Zhaomei Yu, Tian Wang. The Research on the Construction Pattern of Professional Degree Graduate Practice Base, China Agricultural Education, No. 1, (2012), p. 50-52. 
[3] Suli Xing, Jiayu Xiao, Chaoyi Peng, Jingcheng Zeng. Practice Exploration of Graduate Innovation Training Base Construction of University-Enterprise Cooperation, Journal of Higher Education Research, Vol. 35, No. 4, (2012), p. 107-109.

[4] Bin Xu, Cai Gao, Yuchao Niu, Qingzhou Sun. Thinking on Off-Campus Training Base Construc- tion of Postgraduate under the New Situation, Modern Education Science, No. 1, (2009), p. 86-90.

[5] Li Pan, Guozhong Chai, Xudong Peng. The Research on Characteristics, System and Strategy of Postgraduate Training Base Construction, Journal of Zhejiang university of technology (social science edition), Vol. 11, No. 1, (2012), p. 51-55. 